\title{
DRUG UTILIZATION STUDY ON ORAL HYPOGLYCEMIC AGENTS IN TYPE 2 DIABETIC PATIENTS OF TERTIARY CARE HOSPITAL
}

\author{
SARAGADAM BHUVANESWARI* \\ Department of Pharm D, Vignan Institute of Pharmaceutical Technology, Duvvada, Visakhapatnam, Andhra Pradesh, India. \\ Email: saragadambhuvana29@gmail.com
}

Received: 23 January 2020, Revised and Accepted: 02 April 2020

\section{ABSTRACT}

Objective: The main objective of the study is to determine the patient demographic characteristics, inspect prescription patterns of oral hypoglycemic agents, and distribution of comorbid conditions in the outpatient department (OPD) of Visakha Institute of Medical Sciences (VIMS), Visakhapatnam.

Methods: A prospective observational study was conducted in patients with established type 2 diabetes mellitus (n=185) visiting OPD who were interviewed using a structured questionnaire during the period September-December 2019. Statistical analysis used is Chi-square test, mean \pm standard deviation.

Results: The majority of type 2 diabetic patients in VIMS were treated with double-drug therapy. The most commonly prescribed class of oral hypoglycemic agents were biguanides (metformin) followed by sulfonylureas (glimepiride), thiazolidinediones (pioglitazone), alpha-glucosidase inhibitor (voglibose), and dipeptidyl peptidase-4 inhibitor (vildagliptin).

Conclusion: Our study concluded that diabetes mellitus is more prevalent in females than in males, mostly seen in the age group of 50-59 years(y) old patients. Glycemic levels are under control in patients who show good adherence to treatment and with lifestyle modifications. Due to lack of awareness, many patients are with uncontrolled glycemic levels so proper patient educated should be provided.

Keywords: Diabetes mellitus, Hyperglycemia, Oral hypoglycemic agents, Questionnaire, Prospective study, Insulin resistance, International Diabetes Foundation, Indian Heart Association, Coexisting illness, Drug therapy regimen.

(C) 2020 The Authors. Published by Innovare Academic Sciences Pvt Ltd. This is an open access article under the CC BY license (http://creativecommons. org/licenses/by/4. 0/) DOI: http://dx.doi.org/10.22159/ajpcr.2020.v13i5.36919

\section{INTRODUCTION}

Diabetes mellitus (DM) is a group of metabolic disorders characterized by hyperglycemia and abnormalities in carbohydrate, fat, and protein metabolism [1,2] resulting from defects in insulin secretion, insulin action, or both $[3,4]$

Chronic condition of diabetes is associated with long-term damage and dysfunction, failure of various organs, especially blood vessels, eyes, kidneys, nerves, and heart. To prevent the risk of long-term complications, there is a need for appropriate medical care and patient self-management education [4]. Until recently, India had more diabetics than any other country in the world, according to the International Diabetes Foundation diabetes currently affects more than 63 million Indians, which is more than $7.4 \%$ of the adult population, nearly 1 million Indians die due to diabetes every year. Indian Heart Association shows that India is estimated to be hoe to 110 million individuals with diabetes by 2035 [5].

The high incidence is attributed to a combination of genetic susceptibility and adoption of high calorie, low activity. Because of the following reasons, Indians have a low-risk threshold for diabetes: Overweight, higher insulin resistance, lifestyle, higher central obesity for a given BMI, a higher fat mass, lower age of onset, and an occurrence at lower body mass index (BMI > 23). Oral hypoglycemic drugs are used in the treatment of diabetes, which is a disorder involving resistance to insulin secretion [3-6].

At present, among many classes of $\mathrm{OHA}$, sulfonylureas and biguanides class of drugs are most commonly prescribing and for monotherapy, metformin is prescribing mostly followed by glimepiride, pioglitazone, and vildagliptin.

Drug utilization is defined as the distribution, marketing, prescription, and use of drugs in the society, resulting in medical and social consequences. This type of study will create a sound sociomedical and sound economic basis for health-care decision-making (Table 1).

The main aim of this drug utilization study is to assess patient adherence to therapy, the outcome of the drug therapy regimen, how the OHA is prescribing, OHA is prescribing properly or not, and whether drug therapy is rational or not.

\section{METHODS}

The study was carried out at the Department of Endocrinology in Visakha Institute of Medical Sciences (VIMS), Visakhapatnam, to determine patient demographic characteristics, analyze prescription patterns of oral hypoglycemic agents, and distribution of comorbid conditions in the outpatient department. All patients with established type 2 diabetes attending the endocrinology department in the hospital were included in the study during the period September-December 2019.

Information on age, gender, weight, family history, blood sugar levels, glycosylated hemoglobin (HBA1c) levels, and oral hypoglycemic agents was documented. The patient counseling was conducted using a structured questionnaire (open question method):

- Do you forget to take your medicine?

- Are you careless about taking your medicine?

- When you feel good, do you sometimes stop taking medicine?

- Sometimes if you feel worse while taking medicine, do you stop taking it?

A higher score on the scale of $0-4$ indicates better adherence to treatment (yes $=0 ;$ no=1) $[6,7]$.

The study data were analyzed using the Chi-square test that was used for categorical data to test for the association.

\section{Ethical approval}

This study was approved by the ethical committee of the hospital VIMS.

\section{RESULTS}

Gender distribution of patients

Gender distribution of patients: It is found that diabetes is most commonly occurring in females than males (Fig. 1). 
Table 1: List of oral hypoglycemic agents and their classes [3,4]

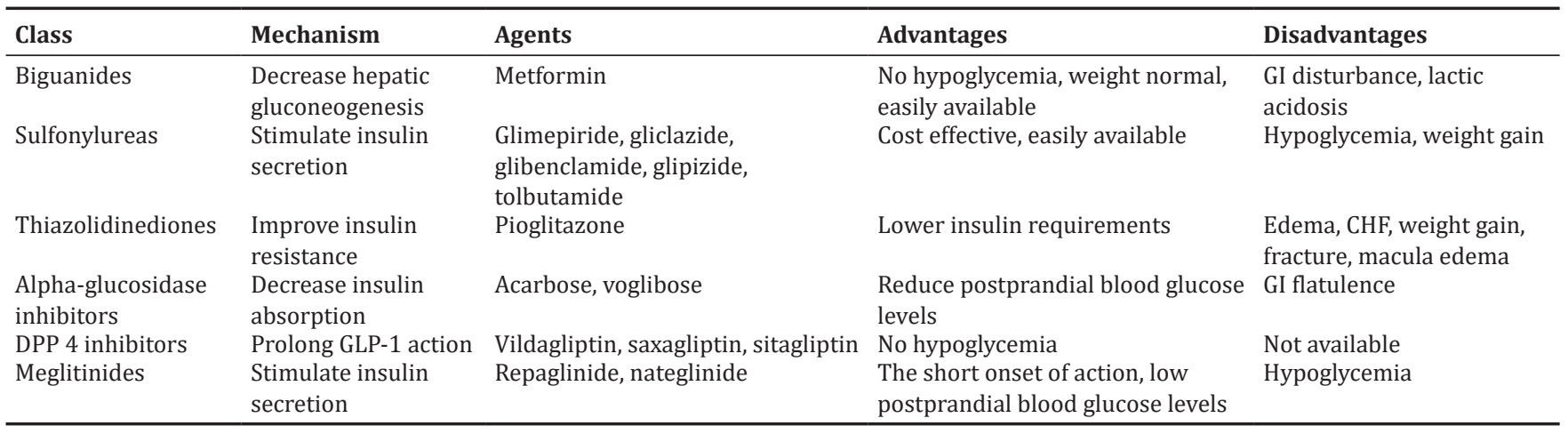

Family history of diabetes mellitus

An analysis of the questionnaire revealed that among 185 diabetic patients, $104(56.2 \%)$ patients had a family history of diabetes. The percentage of patients with no family history of diabetes was found to be $81(43.8 \%)$.

\section{Age distribution of patients}

Diabetic patients who visited the endocrinology department were in the age group ranging from 30 to 80 years old (Fig. 2).

\section{Social history}

Among 59 (32\%) male diabetic patients, $51 \%$ of patients were smokers and $30 \%$ of patients were alcoholics.

Patients who are chronic alcoholic their blood sugar levels were found to be $>270 \mathrm{mg} / \mathrm{dl}$ even though patients are on multiple drug therapy [8].

These patients are counseled to reduce the intake of alcohol and smoking by showing their blood sugar levels and also risk behind abruptly stop smoking and alcohol which will cause withdrawal symptoms such as nausea, anorexia, confusion, palpitations, and seizures.

\section{Distribution of coexisting illnesses}

Distribution of coexisting illnesses: among $(n=185)$ diabetic patients $57 \%$ had associated hypertension, $40 \%$ had associated dyslipidemia, and overweight. It is observed that overweight is the main cause of diabetes mellitus in most patients. Many patients are also suffering from other comorbid conditions like thyroid, cardiovascular diseases, stroke, etc. (Fig. 3).

\section{Distribution of drug therapy regimen}

The most commonly prescribed drug for monotherapy is metformin $\mathrm{OD}$ or $\mathrm{BD}$ or insulin and commonly prescribed double-drug therapy is metformin+glimepiride or insulin commonly prescribed triple-drug therapy regimens are metformin+glimepiride+pioglitazone or with insulin or voglibose, but generally for triple- and multiple-drug therapy insulin will not be prescribed. If patient blood sugar levels are high, drug dose should be increased or other classes of the drug should be added. If blood sugar levels low, reduce drug dose or omit a drug [9,10] (Figs. 3 and 4).

\section{Distribution of oral hypoglycemics}

The most commonly prescribed and available OHA in VIMS are metformin, glimepiride, pioglitazone, voglibose, and vildagliptin (Fig. 5).

\section{Adherence to treatment}

An analysis of the questionnaire revealed [10] (Fig. 6):

\section{Optimal glycemic control}

Among $\mathrm{n}=185$, type- 2 diabetic patients who are receiving OHA 111 (60\%) had controlled optimal glycemic levels and 74 (59\%) had inadequately controlled glycemic levels [11] (Figs. 7 and 8).

Association between optimal glycemic levels was statistically significant in diabetic patients on antidiabetic therapy with lifestyle modifications

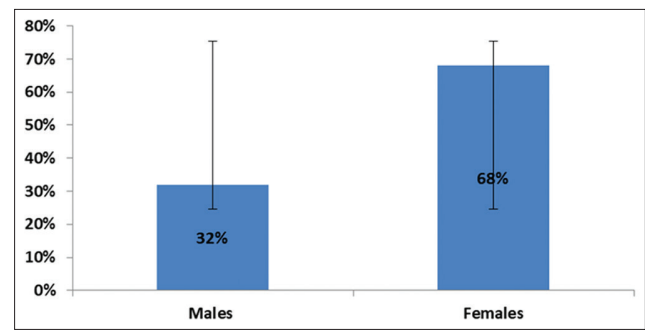

Fig. 1: Gender distribution among type-2 diabetic patients [7]. One hundred and eighty-five diabetic patients were evaluated during the study period September-December, of whom 59 (32\%) patients were male and $126(68 \%)$ patients were female



Fig. 2: Age distribution among type-2 diabetic patients [7]. Among 185 diabetic patients, the age group of 30-39 years included $10(5 \%)$ patients. The age group of $40-49$ years included $57(31 \%)$ patients. The age group of 50-59 years included $65(35 \%)$ patients. The age group of 60 years and above included $46(29 \%)$ patients. Most of the diabetic patient is seen in the age group of 50-59 years old with the mean age of $44.5 \pm 24.2$

$(\mathrm{p}=0.014)$; however, this association with therapy type and other data was not significant statistically ( $p>0.05$ ) (Table 2, Figs. 9 and 10).

\section{DISCUSSION}

This study showed that the majority of diabetic patients ranged between 50 and 60 years old with a mean age of $44.5 \pm 24$.2. While Moradi et al. [12] also concluded that diabetes was more frequent in the age group of 50-60 years which is similar to our study, these reports showed that diabetes starts in lower ages in our society that shows the need for screening for diabetes from an early age ( $>45$ years), especially patients who have a family history [13] of diabetes mellitus and cardiovascular diseases.

Our results showed that diabetes is more prevalent in females than in males which were not agreed with the results of other studies [14]. The risk of type 2 diabetes is $1.76 \%$ greater in females compared to males in our country [15]. This may be related to the fact that obesity, hypertension, and cardiovascular diseases because they normally less physical activity compared to men, so weight control programs and following lifestyle modifications are strongly recommended in this population. 




Fig. 3: Percentage of comorbidities among type-2 diabetic patients [8]. Among 185 patients, 107 (57.8\%) patients had associated hypertension, $74(40 \%)$ patients had associated dyslipidemia,

$44(23.7 \%)$ patients had associated cardiovascular disease, 54 (29\%) patients had associated thyroid problems, 48 (26\%) patients had obesity, $26(14 \%)$ patients had associated stroke, $15(8 \%)$ patients had associated asthma, and $9(5 \%)$ patients had associated filariasis with the mean standard deviation of $38.5 \pm 23$

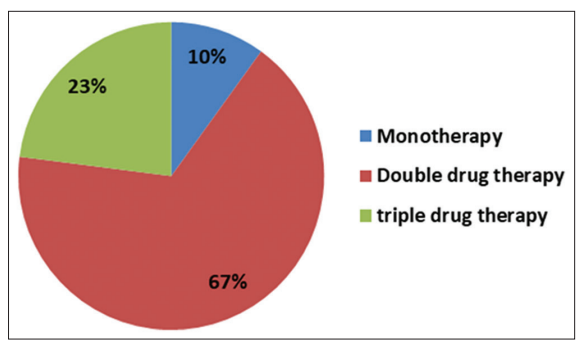

Fig. 4: Drug therapy regimen [8]. The majority (67\%) of patients were on double-drug therapy, $23 \%$ were prescribed with tripledrug therapy, and $10 \%$ were prescribed monodrug therapy with the mean standard deviation $61.1 \pm 55.4$

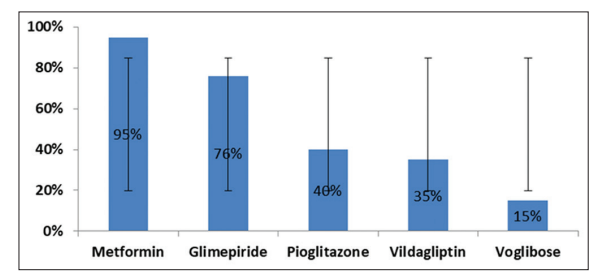

Fig. 5: Percentage of oral hypoglycemic agents. Among total oral hypoglycemics, metformin accounted for $\mathbf{9 5 \%}$ followed by glimepiride $76 \%$, pioglitazone $40 \%$, vildagliptin $35 \%$, and voglibose $18 \%$

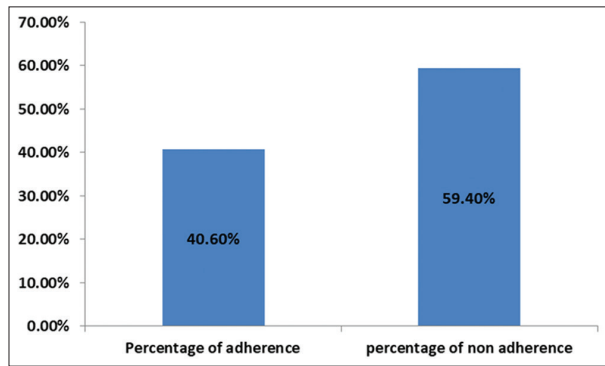

Fig. 6: Percentage of patient's adherence to treatment [10]. Among 185 of diabetic patients, only $75(40.6 \%)$ patients showed good adherence to treatment and the remaining $110(59.40 \%)$ showed non-adherence

to the treatment with a mean standard deviation of $92.5 \pm 22.7$

This study shows that biguanides were the most commonly prescribed class followed by sulfonylureas were the most commonly prescribed class of drugs which was similar to a previous study [16-18]. This reflects that biguanides and sulfonylureas are the choices of most physicians in the treatment of type 2 diabetes mellitus. Metformin (biguanide) 95\% was the most common oral hypoglycemic agent to be prescribed which is similar to several studies [6,18-21] followed by glimepiride (sulfonylureas) $76 \%$. The study documented low prescribing frequency of newer oral hypoglycemic agents such as pioglitazone and vildagliptin, they were used in a combination with sulfonylureas or biguanides to achieve better glycemic control which was similar to the previous studies $[6,16]$.

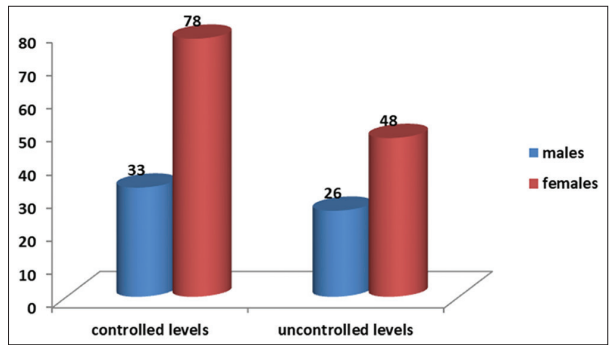

Fig. 7: Among 126 female patients and 59 male patients, 78 female patients and 26 male patients are under glycemic control which is not significant statistically $(p=0.897)$

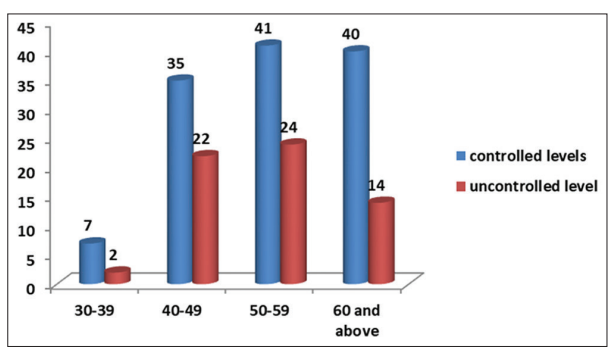

Fig. 8: Patients of the age group of 30-39 years are mostly under glycemic control, some patients of age group of 40-49 years, 5059 years, and 60 and above years old are under optimal glycemic control, and some are not under optimal controlled levels, the association is statistically not significant $(p=0.896)$

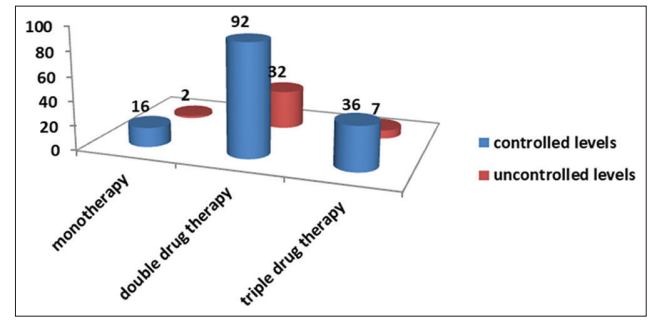

Fig. 9: Patients under double-drug therapy regimen are showing good glycemic control (92 patients) than triple-drug therapy. Patients under monotherapy are not showing a proper glycemic control and the association is not statistically significant $(p=0.696)$

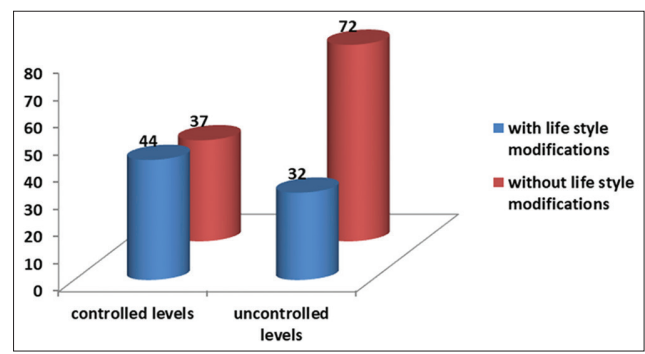

Fig. 10: Patients with lifestyle modifications are showing good glycemic control (76 patients) and patients without lifestyle modifications are not under glycemic control (109 patients). This shows that many patients need to adopt good lifestyle modifications and this association is statistically significant $(p=0.014)$

In this study, drugs were prescribed by generic name which is a most commonly advisable method for easy understanding and to avoid patient and pharmacist-related errors. In this study, drugs were prescribed from the national essential drug list which shows the awareness and selection of drugs from an essential drug list for rational use of drugs.

About $60 \%$ of patients on antidiabetic therapy had controlled optimal glycemic levels, while $40 \%$ had inadequate/uncontrolled glycemic levels. Many studies have documented from $52 \%$ to $88 \%$ which were higher than our studies [22-26], these variations are may be due to differences in methods 
Table 2: Characteristics of diabetic patients based on glycemic control

\begin{tabular}{|c|c|c|c|c|}
\hline \multirow{2}{*}{$\begin{array}{l}\text { Patient } \\
\text { characteristics }\end{array}$} & \multicolumn{2}{|c|}{ Glycemic level } & \multirow{2}{*}{$\begin{array}{l}\text { Total } \\
(n=185)\end{array}$} & \multirow[t]{2}{*}{$p$ value } \\
\hline & Controlled & Uncontrolled & & \\
\hline \multicolumn{5}{|l|}{ Gender } \\
\hline Male & 33 & 26 & 59 & 0.897 \\
\hline Female & 78 & 48 & 126 & \\
\hline \multicolumn{5}{|l|}{ Age (years) } \\
\hline $30-39$ & 7 & 2 & 9 & 0.896 \\
\hline $40-49$ & 35 & 22 & 57 & \\
\hline $50-59$ & 41 & 24 & 65 & \\
\hline 60 above & 40 & 14 & 54 & \\
\hline \multicolumn{5}{|l|}{ Therapy type } \\
\hline Monotherapy & 16 & 2 & 18 & 0.696 \\
\hline $\begin{array}{l}\text { Double-drug } \\
\text { therapy }\end{array}$ & 92 & 32 & 124 & \\
\hline $\begin{array}{l}\text { Triple-drug } \\
\text { therapy }\end{array}$ & 36 & 7000 & 43 & \\
\hline \multicolumn{5}{|l|}{$\begin{array}{l}\text { Antidiabetic } \\
\text { therapy }\end{array}$} \\
\hline $\begin{array}{l}\text { With lifestyle } \\
\text { modifications }\end{array}$ & 44 & 32 & 76 & 0.014 \\
\hline $\begin{array}{l}\text { Without } \\
\text { lifestyle } \\
\text { modifications }\end{array}$ & 37 & 72 & 109 & \\
\hline
\end{tabular}

of data collection, measurement of blood glucose levels such as pre-prandial and post-prandial levels, and the difference in the population surveyed.

The most prevalent antidiabetic therapy was double-drug therapy, the most commonly prescribed double-drug therapy is metformin+glimepiride or insulin or pioglitazone or vildagliptin. However, the study by Willey et al. has shown good glycemic control on monotherapy [24]. This study shows glycemic control with monotherapy and combination therapy was not significant statistically $p>0.05(0.696)$ and we found a statistically significant $(\mathrm{p}<0.05)$ association between glycemic control and antidiabetic therapy with lifestyle modifications. Thus, from the above results, it shows that lifestyle modifications with antidiabetic therapy have the potential to improve glycemic control in patients with type 2 diabetes mellitus [27-29].

\section{CONCLUSION}

From this study, it is concluded that double-drug therapy was more used than monotherapy, in this, metformin and glimepiride combination drugs were commonly used followed by metformin and pioglitazone, mostly prescribing in an oral dosage form. Patients with lifestyle modifications showed controlled blood sugar levels than patients without lifestyle modifications. Polypharmacy is a big problem, especially for elderly patients, due to illiteracy, lack of awareness, and negligence, many patients show non-adherence to the treatment. This study mainly focused on the need for patient education or counseling on diabetes mellitus disease, the use of antidiabetic and concomitant drugs, monitoring of blood glucose and HBA1c levels, diet control, physical activity, and complications of diabetes mellitus, by providing the above information can reduce the chance of medication errors and can improve adherence to treatment.

\section{ACKNOWLEDGMENT/FUNDING}

I would like to thank VIMS Hospital, Endocrinology Department doctor and other staff members for granting the permission.

\section{AUTHORS' CONTRIBUTIONS}

Data collection, literature search, design, analysis, interpretation of data, and proofreading done by Saragadam Buvaneswari.

\section{CONFLICTS OF INTEREST}

No conflicts of interest.

\section{REFERENCES}

1. Balaram G, Ahikari A, Vidhyasagar G. Research gate. The Indian Journal Of Hospital Pharmacy. 2011;48:32-4.
2. Pankaj C, Satendra S, Dhananjay P, Kumud R, Rajmangal C, Bhanu P. A prospective study on drug utilization pattern of anti-diabetic drugs in a tertiary care teaching hospital of eastern Uttar Pradesh, India. Int J Res Med Sci 2019;7:669.

3. Tripathi K. Essentials of Medical Pharmacology. $7^{\text {th }}$ ed. New Delhi: JAYPEE; 2013.

4. DiPiro J. Pharmacotherapy: A Pathophysiologic Approach. $9^{\text {th }}$ ed. United States: Content Technologies; 2012.

5. Diabetes; 2019. Available from: http://www.en.wikipedia.org. [Last accessed on 2004 May].

6. Sultana G, Kapur P, Aqil M, Alam M, Pillai K. Drug utilization of oral hypoglycemic agents in a university teaching hospital in India. J Clin Pharm Ther 2010;35:267-77.

7. Boccuzzi S, Wogen J, Fox J, Sung J, Shah A, Kim J. Utilization of oral hypoglycemic agents in a drug-insured U.S. population. Diabetes Care 2001;24:1411-5.

8. Mogali S, Bhushan A, Ratnakar J. Drug utilization study and adverse drug reactions of oral antidiabetics among Type 2 diabetes mellitus patients in tertiary care hospital. Int J Basic Clin Pharmacol 2019;8:699-703.

9. Khalam A, Dilip C, Shinu C. Drug use evaluation of diabetes mellitus in hospitalized patients of a tertiary care referral hospital. J Basic Clin Physiol Pharmacol 2012;23:173-7.

10. Kumar S. A study on drug utilization of oral hypoglycemic agents in Type-2 diabetic patients. Res Gate 2011;4:60-4.

11. Agarwal A, Jadhav P, Deshmukh Y. Prescribing pattern and efficacy of anti-diabetic drugs in maintaining optimal glycemic levels in diabetic patients. J Basic Clin Pharm 2014;5:79-81.

12. Moradi M, Mousavi S. Drug use evaluation of diabetes mellitus in nonhospitalized patients. Int J Pharm Pharm Sci 2016;8:336-41.

13. Chaturvedi R, Desai C, Patel P, Shah A, Dikshit RK. An evaluation of the impact of antidiabetic medication on treatment satisfaction and quality of life in patients of diabetes mellitus. Perspect Clin Res 2018;9:15-22.

14. Konuru V, Reedy TR. Comparative study of oral hypoglycemic agents in Type-2 diabetes obese patients. Asian J Pharm Clin Res 2018;11:505.

15. Mohammad H, Thunga T, Ateendra J, Surulivelrajan M. Study on prescribing patterns of anti-diabetic drugs. Int J Pharm Pharm Sci 2016;9:194.

16. Hasamnis A, Patil S. Prescription pattern study in Type 2 diabetes mellitus in an Indian referral hospital. Int J Pharmacol 2009;7:1.

17. Sutharson L, Hariharan RS, Vamsadhara C. Drug utilization study in diabetology outpatient setting of a tertiary hospital. Indian J Pharmacol 2003;35:237-40

18. Truter I. An investigation into antidiabetic medication prescribing in South Africa. J Clin Pharm Ther 1998;23:417-22.

19. Adibe MO, Aguwa CN, Ukwe CV, Okonta JM, Udeogaranya PO. Outpatient utilization of anti-diabetic drugs in South-Eastern Nigeria. Int J Drug Dev Res 2009;1:27-36.

20. Rajeshwari S, Adikhari P, Pai MR. Drug utilization study in geriatric Type 2 diabetic patients. J Clin Diagn Res 2007;1:440-3.

21. Hassan Y, Mathialagan A, Awaisu A, Aziz NA, Yahaya R, Salhani A. Trend in the use of oral hypoglycemic agents in an outpatient pharmacy department of a tertiary hospital in Malaysia (2003-2006). Asian J Pharm Clin Res 2009;2:40-6.

22. Mendes AB, Fittipaldi JA, Neves RC, Chacra AR, Moreira ED Jr. Prevalence and correlates of inadequate glycaemic control: Results from a nationwide survey in 6,671 adults with diabetes in Brazil. Acta Diabetol 2010;47:137-45.

23. Patel B, Oza B, Patel KP, Malhotra SD, Patel VJ. Pattern of antidiabetic drugs use in Type-2 diabetic patients in a medicine outpatient clinic of a tertiary care teaching hospital. Int J Basic Clin Pharmacol 2013;2:485-91.

24. Willey CJ, Andrade SE, Cohen J, Fuller JC, Gurwitz JH. Polypharmacy with oral antidiabetic agents: An indicator of poor glycemic control. Am J Manag Care 2006;12:435-40.

25. Ben Abdelaziz A, Soltane I, Gaha K, Thabet H, Tlili H, Ghannem H. Predictive factors of glycemic control in patients with Type 2 diabetes mellitus in primary health care. Rev Epidemiol Sante Publique 2006;54:443-52.

26. Moreira ED Jr., Neves RC, Nunes ZO, de Almeida MC, Mendes AB, Fittipaldi JA, et al. Glycemic control and its correlates in patients with diabetes in Venezuela: Results from a nationwide survey. Diabetes Res Clin Pract 2010;87:407-14.

27. Effect of intensive blood-glucose control with metformin on complications in overweight patients with Type 2 diabetes (UKPDS 34). UK prospective diabetes study (UKPDS) group. Lancet 1998;352:854-65

28. Intensive blood-glucose control with sulphonylureas or insulin compared with conventional treatment and risk of complications in patients with Type 2 diabetes (UKPDS 33). UK prospective diabetes study (UKPDS) Group. Lancet 1998;352:837-53

29. DeFronzo RA. Pharmacologic therapy for Type 2 diabetes mellitus. Ann Intern Med 1999;131:281-303. 